\title{
Approaches for Building Information Systems for Monitoring the Realization of Students
}

Received: 17.05.2021

Available online: 29.09.2021

\section{Rosen Kirilov}

\begin{abstract}
The article is dedicated to the methodological and technological issues of building information systems for tracking the realization of graduating students. This is an important issue for the field of higher education, as it has a direct bearing on the quality of the higher education provided. The higher the quality of education is, the easier and more successful the realization of the students can be. In this way, the results of the student performance survey can be used as an indicator for the introduction of corrective policies. Based on a literature research, the study proposes a specially developed methodology consisting of five methods. Each of them is described, and from a software point of view the implementation of the last of them is the most complex. An indicative framework of three main stages and tasks in them is proposed, which allow the realization of the designed information system. In the empirical part of the research special attention is paid to the software implementation of the most complex of the proposed methods, and also the results of its application are presented.
\end{abstract}

In conclusion, opportunities for improvement and development of the methodology are proposed.

Keywords: information technology, software, career development, career centers, higher schools

JEL: I23, L86

\section{Introduction}

The modern development of the economy and public services requires widely trained specialists with higher education. The labor market is experiencing a constant shortage of highly qualified specialists. This poses several challenges to the field of higher education. It should not just train staff, but also train staff to get a quick and very concrete realization on the labor market. In this sense, the realization of graduates is a very serious indicator of the quality of educational services provided. For these reasons, universities face the challenge of having information about the realization of their graduates. This information should be the basis for management decisions in the activities of the respective higher education institution. For these reasons, the following main goal of the current research can be

\footnotetext{
${ }_{1}^{1}$ Associate Professor, PhD, Department of Information Technologies and Communications, University of National
} and World Economy. 


\section{Articles}

defined: based on the experience gained, to propose a methodology and software tools for the implementation of an information system for tracking the performance of graduates. This objective can be decomposed into the following sub-objectives:

- analysis of the main sources on the issues of the development of information systems for monitoring the realization of the graduates;

- development of a methodology for tracking the implementation;

- software development of components of the proposed methodology, as a basis for building an information system for tracking the implementation.

To achieve the main goal and the defined sub-goals, it is necessary to develop an empirical part of the research, allowing:

- creation of a project specification of the proposed methodological tools;

- software implementation of components and algorithms, allowing the construction of the information system;

- approbation of the software methods and analysis of the obtained results.

The present study also has some limitations that determine its scope:

- for many reasons, it is not possible to fully cover all graduates. Therefore, the main indicator for achieving the effectiveness of the proposed methodological and technological tools is the maximum percentage of students covered by the system;

- the use of data from national registers can be done only if an agreement is reached between the higher education system and the relevant state institutions, as well as in compliance with the relevant rules.
Approaches for Building Information Systems for

Monitoring the Realization of Students

The analyses and researches in the outlined direction can give the methodical and technological basis for the construction of an information system for tracking the realization of the graduates.

\section{Theoretical background}

The problems of the realization of the graduates are widely discussed in the EU member states. As early as 2017, the European Union published an important document called the Council Recommendation of 20 November 2017 on tracking graduates (Publications Office of the EU, 2017). It concludes that "the systems for collecting, analyzing and using data on outcomes for graduates from higher education and vocational education and training are not well developed in many parts of the Union" (p. 1). These findings are based on studies of higher education systems in the Member States. For these reasons, it is becoming increasingly important to determine what data collection methodology should be used to achieve high efficiency. The same document identifies the following types of data to be collected: socio-biographical and socioeconomic information; information on education and training; information on employment or further education and training; relevance of education and training to employment or life-long learning; career progression (Publications Office of the EU, 2017). Another important document of the European Union - Communication from the Commission to the European Parliament, the Council, the European Economic and Social Committee and the Committee of the Regions on achieving the European Education Area by 2025 states that "in 2022, the Commission will take stock of progress made in implementing the recommendation" (p. 23). In the common European space, these processes are 


\section{Articles}

expected to be completed by 2025 . This largely depends on the efforts of each higher education institution in each of the member states.

In their study, Beadle, Vale, MannsbergerNindl, Hannah, Zaidi, Abdallah, and Kottmann (2020) identified several main data sources used by higher education institutions in the European Union, namely: Quantitative surveys; Qualitative surveys; Data matching and Data mining. The survey was conducted among 375 institutions, of which 318 (85\%) indicated Quantitative surveys as the main source. The same study states that about $61 \%$ of the surveyed higher education institutions use only one type of tracking measure. Two tracking measures are used by about $22 \%$, and three tracking measures only by $8 \%$. All these analyses and studies show that the European Commission is paying serious attention to the Member States that efforts should be made to develop effective monitoring systems that include multiple sources, indicators, and benchmarks.

There is no consensus in the literature on the applied methods for monitoring the development of graduates. In his study, Norbert (2017) described three created models. They should consider the following elements: "the responsible institutions, the applied research methods, the surveyed basic population, the surveyed areas and the response rates". In the present study, we support what Orr (2015) described, namely that "the critics of graduate tracking often say that students shouldn't just be viewed as a tool for the labor market". All the described approaches of the world researchers note the high application in practice of data from labor market surveys on graduates. This poses some risks, as there is no direct control over the percentage of respondents and the success of the empirical study.

At the national level in 2017, an audit report of the National Audit Office was published on the research issues (National Audit Office, 2017). It analyzes the system of higher education and makes the relevant recommendations. The report emphasizes the need to build effective systems for monitoring the performance of graduates. The difficulties for higher education institutions to monitor the realization of students migrating abroad are reported. According to the analyses made in this document, a large part of the higher schools gathers information about the realization of the students using their personal contacts and periodical meetings of the graduates. The possibilities for using an alumna system are also considered. The cited report of the National Audit Office states that "in the majority of higher education institutions the data collected by the systems are not exhaustive due to the use of insufficiently reliable methods and sources for their collection" (National Audit Office, 2017).

All studies and analyses show the need to develop methodologies and appropriate software tools for developing effective systems for tracking the performance of graduates.

\section{Methodology for tracking the realization of graduates}

The analyzed research problem requires the development of a comprehensive information system for tracking the realization of graduates. Its main purpose is to constantly provide information on the following issues:

- how many of the graduates have entered the labor market in the first year after graduation? 


\section{Articles}

- what are the main sectors in which the students worked?

- who are the main employers for which the students worked?

- what is the percentage of realized students in the completed specialty?

- what are the main challenges for the realization of the students?

Finding answers to these and other similar questions will provide opportunities for making appropriate management decisions at the university level. These decisions should be aimed at seeking a better realization of students in the labor market, as well as aimed at improving the quality of education.

The studies show that at this stage on the territory of the Republic of Bulgaria there is
Approaches for Building Information Systems for

Monitoring the Realization of Students

no technological possibility for centralized or unified monitoring of student achievement. For these reasons, every university faces the challenge of looking for methodological and software opportunities for the development of independent tracking information systems. On the other hand, to build such an information system, the methodological tools should first be developed to allow:

- digitization of the relevant processes;

- development of specific algorithms for data provision;

- program implementation of the designed algorithms, etc.

In the present study, we believe that the general statement for reaching a solution can be represented graphically in Fig. 1.

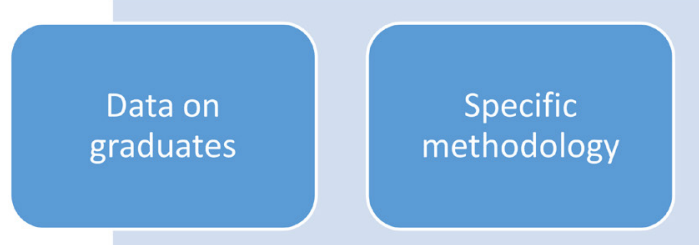

\section{Software}

implementation

of the

methodology and

algorithms
Creating a

conversion

tracking system

Figure 1. Creating a conversion tracking system

As a result of studying the characteristics of the research problem, the present study proposes the development of a specific methodology. Its structure should consist of a group of specialized methods, conditionally divided into two groups:
- using data that are available or provided under relevant procedural rules;

- retrieving data from the web space by appropriate algorithms.

The graphical representation of the proposed methodology is given in Fig. 2. 


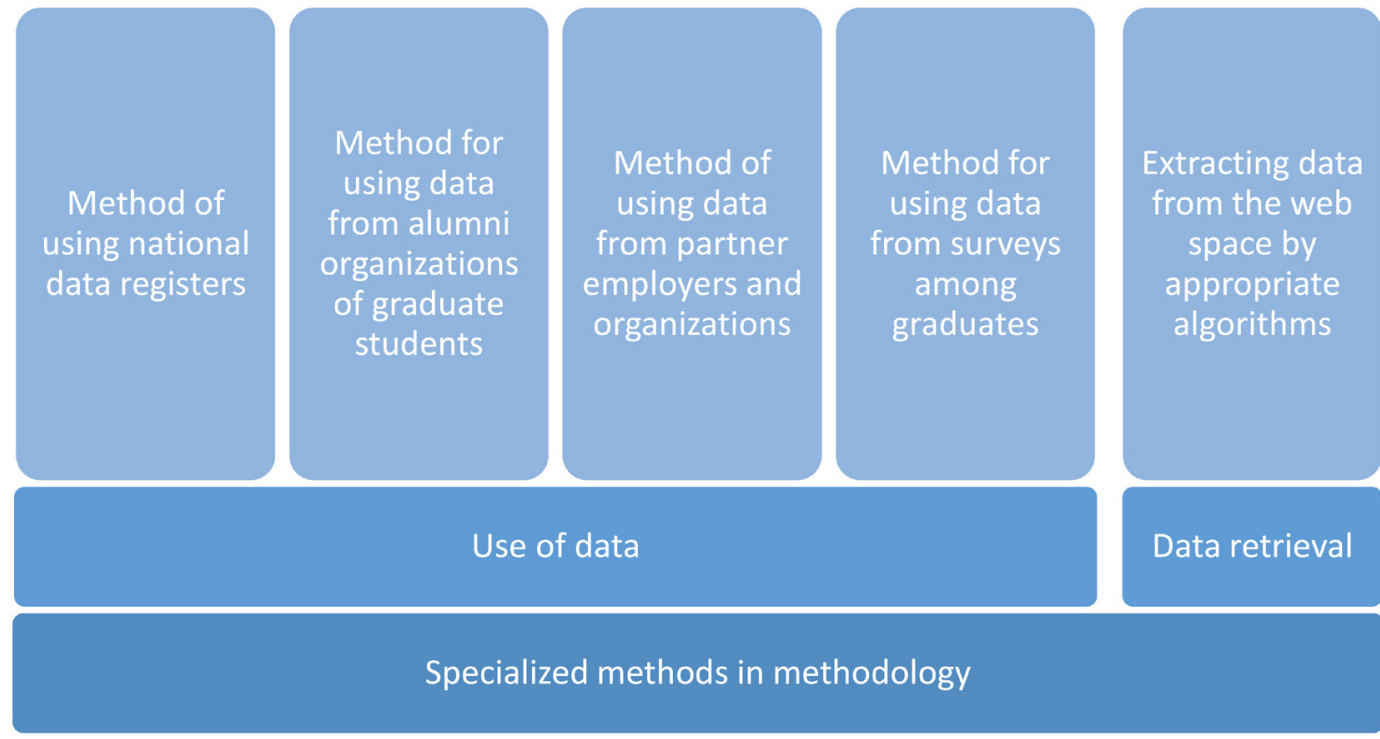

Figure 2. Specialized methods in methodology

The main methods in the methodology are:

- method of using national data registers;

- method for using data from alumni organizations of graduates;

- method for using data from partner employers and organizations;

- method for using data from surveys among graduates;

- method for extracting data from websites and social networks.

The method of using national data registers is related to the need to provide data from national organizations. These may be the National Revenue Agency and the National Social Security Institute. The work of the method is expressed in the comparison of the data for the graduates from the respective higher school and the data from the national register. The comparison should be made according to the main identifier of the persons - Unified civil number. In essence, these are two sets that can intersect. The larger number is for all persons who are insured with the National Revenue Agency. The smaller number is of graduates in the respective year. In case of coincidence of the identifier of a graduate student with the identifier in the national register, an identifier of the employer providing the person shall be extracted from it. In this way a list of graduates who have been realized on the labor market is formed, together with the identifier of the respective employer.

The main challenges to the operation of this method are:

- information cannot be provided about the persons who are not covered by the insurance system and are not insured;

- the information about the students realized abroad is not provided;

- the information about the position in which the respective person works may not be indicative of the compliance with the studied specialty. In this case, an additional analysis of the subject and the main activity of the employer is required;

- the operation of the method is possible only in case of a normatively regulated 


\section{Articles}

agreement between the respective organizations for the use of data from the national registers.

The presented method has a relatively easy software implementation. The problems with its application can be mainly of a methodical nature.

The method for using data from the alumni organizations of the graduate students can function only in developed alumni organizations in the respective higher school. What is special about these organizations is the maintenance of constant communication and contacts with some of the graduates. This type of organization aims to constantly expand its members, organize various events and meetings, and maintain active communication. Alumni organizations can provide data to the graduate tracking system.

The main challenges to the operation of this method are:

- not all graduate students are members of or covered by alumni organizations;

- it is possible that part of the information about the realization of the students is not completely up-to-date;

- the provision of such information depends on the sustained policies of alumni organizations.

The method of using data from partner employers and organizations can be applied only when a register of business partners is built and maintained. There are several prerequisites for achieving the effectiveness of this method:

- existence of a policy for permanent conclusion of partnership agreements between the higher school and the representatives of the business;

- concluding agreements with leading employers;
Approaches for Building Information Systems for

Monitoring the Realization of Students

- presence of clauses in the concluded agreements for provision of data for graduates, etc.

The main challenges to the operation of this method are:

- lack of a unified register of business partners;

- lack of an active policy on concluding partnership agreements;

- lack of an adequate communication policy.

The method of using data from surveys among graduates aims to use data from regular surveys among graduates. In the case of such a policy pursued by the higher school, it can become an effective source of information for the realization of students. Some authors consider the approaches and ways of conducting surveys among relevant target groups (Kirilova, 2020).

The main challenges to the operation of this method are:

- the need to conduct such surveys on a regular basis (e.g., 1 or 2 times a year);

- low activity of respondents due to low motivation;

- preservation of the survey data confidentiality (Naydenov, 2016).

The method of extracting data from websites and social networks is the most independent in terms of subjective reasons. Its justification is related to the possibility of extracting data from the web space for public profiles of realized students. Such data are available in the following types of sources:

- websites of public organizations (ministries, agencies, municipalities, etc.);

- websites of large companies where information about employees is found;

- social media profiles;

- news and news comments;

- forums, etc. 


\section{Articles}

The implementation of this method is possible only with serious software of the proposed algorithms. It is proposed to include the following basic algorithms in this method:

- algorithm for determining the main data sources;

- algorithm for determining the structure of each of the data sources;

- algorithm for extracting data from the specified sources;

- algorithm for creating a database with web search results;

- algorithm for comparing the database with the search results and the target database of graduates.

The next part of the study presents the possibilities for software implementation of some of the proposed methods in the methodology, as well as the results obtained from the approbation of the methods.

\section{Building an information system for tracking the realization of graduates}

The construction of the information system for tracking the realization of the graduates should be divided into certain stages. In view of the goal of this research and in line with the described methodology, the following sequence of stages and tasks for the implementation of the system is proposed (Fig. 3):
Stage of research of the possibilities for building the system
Stage of designing the

architecture and components of the system
Stage of programming

the components of the system

Figure 3. Main stages in building an information system for tracking the realization of graduates

- stage of research, which should create the preconditions for the software implementation of the proposed methods. At this stage the possibilities for building a system for tracking the realization of the graduates are studied;

- stage of designing the architecture and components of the system. This stage should create a complete conceptual and logical design specification of the developed information system;
- stage of programming the components of the system. At this stage, the software implementation of each of the methods and their algorithms is envisaged.

The next part presents the individual tasks and activities that are envisaged in the three stages.

The study phase should implement the following set of tasks:

- study of national and world experience in creating such information systems; 


\section{Articles}

- study of the normative and procedural rules regarding the possibilities for using data from national registers;

- study of the structure of the national data registers and the technological procedures, regarding a potential internet connection with them, etc.

The design stage of the architecture and components of the system should realize the following set of tasks:

- creation of a software description of the main processes for tracking the realization of the graduates;

- development of all components of the proposed methodology for tracking the implementation. This includes the design of all methods and algorithms;

- design of the conceptual and logical project on the basis of the information system data;

- design of a procedure for storage of the extracted data;

- user interface design;

- creation of complete project documentation of the built information system.

The programming stage of the system components should realize the following set of tasks:

- selection of technological and software tools for the implementation of the information system;

- program implementation of the system database;

- program realization of the business logic of the information system;

- program implementation of the user interface of the system;
Approaches for Building Information Systems for

Monitoring the Realization of Students

- testing the information system for tracking the realization of students;

- commissioning of the developed system.

Each of the developed five methods in the composition of the proposed methodology has a specific complexity. The empirical part of the research will present the software implementation of the fifth defined method and the results of its work.

\section{Empirical analysis}

In this part of the study, a prototype experiment was conducted based on the method of extracting data from websites and social networks. The algorithm for method operation is based on the approach defined by Milev (2017) for development of web scraping application. Additional levels have been added to the approach, which realize the connection between the data extracted from online sources and their comparison with the information about graduates that universities should have. Sources suitable for verification are those that have information about the employees of an organization and their education. According to the present study, it is possible to conduct research on this topic and to define the relevant data sources. A necessary condition for the proper operation of the method is the accuracy of the information published within the relevant platforms. For this reason, it is good to include in the sources mainly those in which the published information goes through some preliminary verification of its authenticity. The algorithm for method operation for the method of extracting data from websites and social networks is presented in Fig. 4. 


\section{Articles}

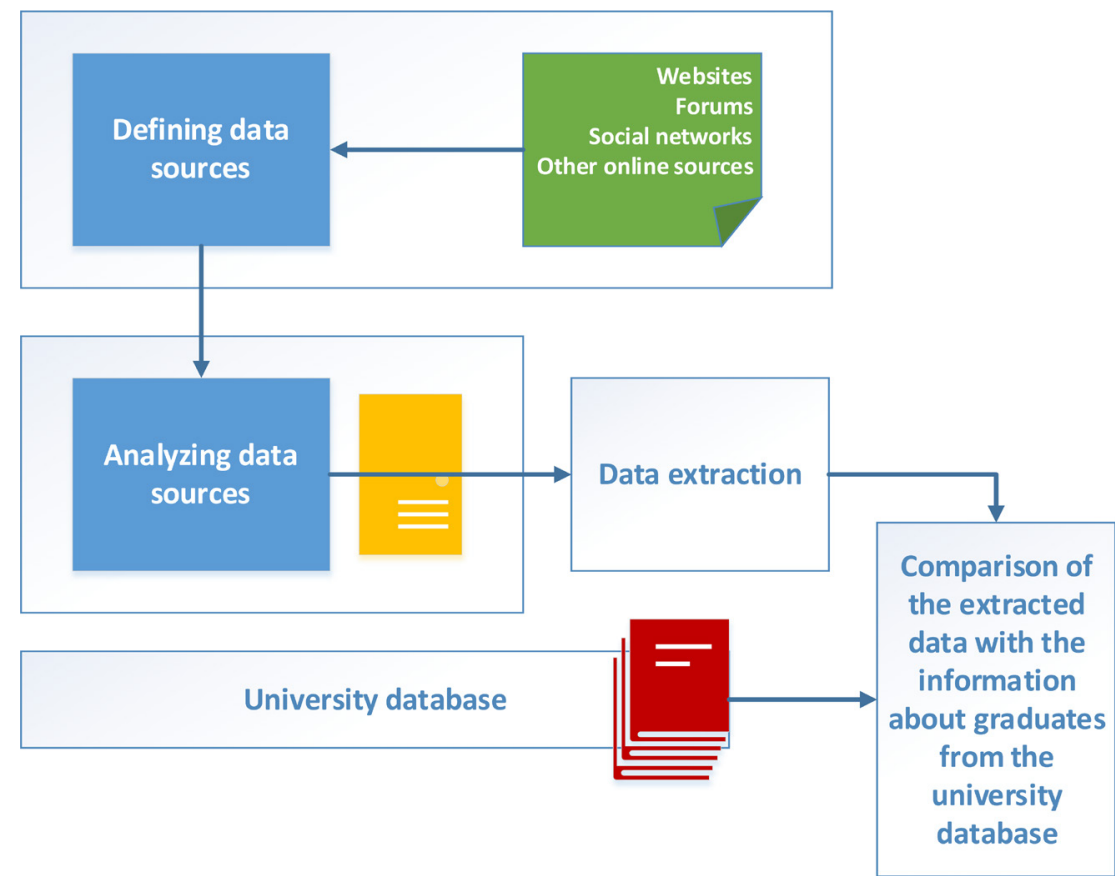

Figure 4. The algorithm for method operation

An experiment has been developed "UNWE". This criterion must be present, and according to the presented algorithm. It involves searching for information in a predefined list of data sources. The search criteria include terms such as "graduate" in all their forms of speech. The main criterion is of the other criteria it is sufficient for only one to be present- any one of them. The period set in the experiment covers January 2019 - April 2021. Based on this experiment, the results presented in Table 1 were obtained.

Table 1. Data from the empirical analysis

\begin{tabular}{|c|c|}
\hline Month & Publications \\
\hline January 2019 & 93 \\
\hline February 2019 & 100 \\
\hline March 2019 & 178 \\
\hline April 2019 & 146 \\
\hline May 2019 & 132 \\
\hline June 2019 & 71 \\
\hline July 2019 & 150 \\
\hline august 2019 & 82 \\
\hline September 2019 & 175 \\
\hline October 2019 & 180 \\
\hline
\end{tabular}




\begin{tabular}{|c|c|}
\hline Month & Publications \\
\hline November 2019 & 186 \\
\hline December 2019 & 109 \\
\hline January 2020 & 142 \\
\hline February 2020 & 77 \\
\hline March 2020 & 53 \\
\hline April 2020 & 96 \\
\hline May 2020 & 82 \\
\hline June 2020 & 79 \\
\hline July 2020 & 179 \\
\hline August 2020 & 35 \\
\hline September 2020 & 105 \\
\hline October 2020 & 187 \\
\hline November 2020 & 142 \\
\hline December 2020 & 81 \\
\hline January 2021 & 58 \\
\hline February 2021 & 123 \\
\hline March 2021 & 239 \\
\hline April 2021 & 136 \\
\hline
\end{tabular}

The data show that for the whole period of the experiment the resulting publications are a total of 3416 . This leads us to believe that the experiment was successful, because after refining the sources and criteria for extracting data from them, the results should increase. In the context of the present study, the data obtained can be compared with the data from other methods defined in the paper. The data model, on which the empirical part was developed, is presented in Fig. 5.

The developed model consists of five objects. Four of these sites present the period, publications, data sources and criteria for conducting the study. The fifth object is an association between the period, the publications, and the criteria. The period represents a month and a year. Publications are characterized by author, title, text, date, and link. Data sources have a type and address. The type is one of the listed - website, forums, social networks, other online sources. The criteria are the relevant keywords for conducting the study. One source may have zero or many publications, while one publication belongs to exactly one source. The associative object clarifies how many times which criterion for the respective period in which publication occurs. This is the central object in the presented data model. The empirical study itself is based on this data model. Its graphic expression is presented in Fig. 6.

In addition to the number of publications that meet the set criteria for data extraction, the graph also shows the number of occurrences of the relevant criteria. The red curve shows the number of publications 
Articles

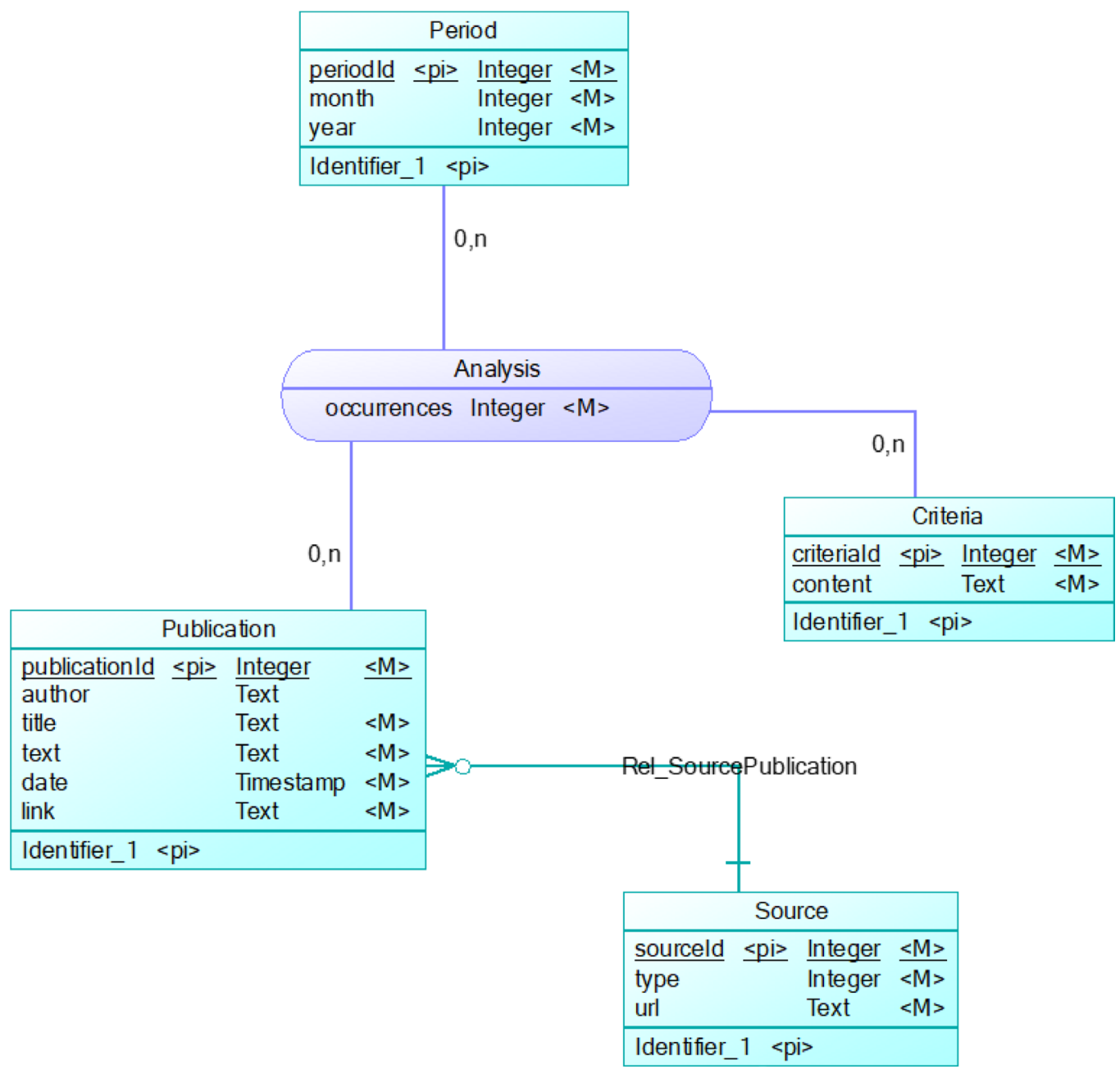

Figure 5. Data model of the empirical analysis

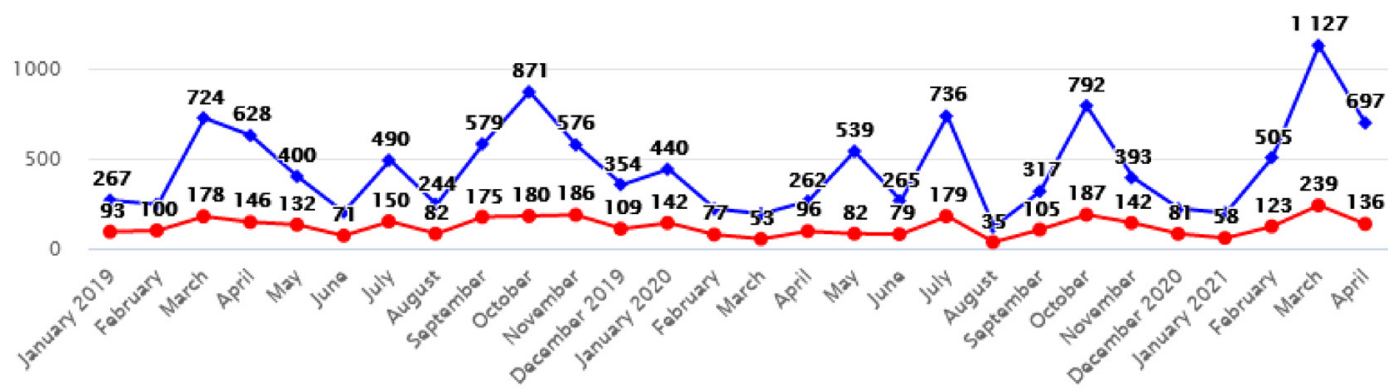

Figure 6. Graphically distributed data from Table 1 


\section{Articles}

and the blue curve shows the number of occurrences. It is noteworthy that the number of mentions significantly exceeds the number of publications. This means that data from more than one university graduate can be found in one extracted publication. All this gives us a reason to believe that the method of extracting data from websites and social networks is essential within the methodology for tracking the realization of graduates.

\section{Opportunities for improvement of the methodological and software tools}

Like any methodology, the proposed one can be developed and improved. The main directions of development are:

- to enable the full software implementation of all designed methods, it is necessary to offer a unified approach to describe each of them. This can be achieved by developing a single template to specify each method. It is appropriate for this template to include the following set of characteristics: name of the method; position of the method in the methodology; input data for the method; components of the method; initial data from the implementation of the method, etc.;

- extension in the composition of the methods. This can be achieved by identifying additional data provision processes;

- extension in the functionality of the designed methods. Such a solution can be realized by changing the algorithms for operation of the proposed methods.

These and other similar measures can be used as a basis for extension and improvement of the proposed methodology based on the results of its approbation.
Approaches for Building Information Systems for

Monitoring the Realization of Students

\section{Conclusion}

The topics discussed in the research are complex. This complexity is determined by the need to study and analyze many different data sources with different structures. Each of these different types of data should be used through specific programming algorithms. In conclusion of the present scientific research the following main conclusions can be drawn:

- the proposed methodology can be used as a basis for creating a comprehensive information solution for tracking the realization of graduates;

- it is necessary to make efforts by all participants in the process for constant collection of data on the implementation.

The formulated conclusions from the research and the analyses can be used as a good basis for building a general architectural solution of an information system for tracking the realization of the students, with which the main goal of the research has been achieved. The proposed empirical part should be used to automate the rest of the proposed methods. Achieving a high efficiency of the system can be considered as an important prerequisite for improving the quality of higher education in Bulgaria.

\section{References}

Audit report 0300100716 for performed performance audit "Monitoring the realization and migration of higher education graduates " for the period from 01.01.2013 to 31.12.2015, adopted by Decision № 068 of 24.04.2017 of the National Audit Office, https://www.bulnao. government.bg/bg/articles/realizaciqtana-visshistite-v-stranata-se-nabljudavauspeshno-no-lipsva-informaciq-zamigracionnite-procesi-sred-tqh-1742 [Online, Accessed May 2021] 


\section{Articles}

Beadle, S., Vale, P., Mannsberger-Nindl, S., Hannah, A., Zaidi, A., Abdallah, C., Kottmann, A., 2020, Mapping the state of graduate tracking policies and practices in the EU Member States and EEA countries, Publications Office of the European Union, Print ISBN 978-92-76-18129-3, doi:10.2766/09070 NC-01-20-250-EN-C, PDF ISBN 978-92-7618130-9 doi:10.2766/62505 NC-01-20-250EN-N, https://ec.europa.eu/education/news/ graduate-tracking-results-2020_en [Online, Accessed May 2021]

Communication from the Commission to the European Parliament, The Council, The European Economic and Social committee and the Committee of the regions on achieving the European Education Area by 2025, https:// ec.europa.eu/education/sites/default/files/ document-library-docs/eea-communicationsept2020_en.pdf [Online, Accessed May 2021]

Council Recommendation of 20 November 2017 on tracking graduates, OJ C 423, 9.12.2017, https://eur-lex.europa.eu/legalcontent/EN/TXT/? uri=CELEX\%3A3201 7H1209\%2801\%29 [Online, Accessed May 2021]

Kirilova, K., 2020, Possibilities for Improvement of Administrative Processes in Local Administration, Economic and Social Alternatives, Issue 1, 2020, pp. 53 - 70, ISSN (print): 1314-6556, ISSN (online): 2534-8965, DOI: https://doi.org/10.37075/ISA.2020.1.05.
Milev, P., 2017, Conceptual approach for development of web scraping application for tracking information, Economic Alternatives, Issue 3, 2017, pp. 475 - 485, ISSN 1312-7462. Naydenov, A., 2016, Possibilities for Improvement of the Statistical Confidentiality Methods and Approaches, Economic and Social Alternatives, Issue 1, 2016, pp. 13 23, ISSN 1314-6556, https://www.unwe.bg/ alternativi/bg/journalissues/article/8638

Norbert, Sipos. (2017). Graduate Career Tracking System Across the World-as Information Systems in higher Education Decision-making Process. 22, https://www. researchgate.net/publication/322715105_ Graduate_Career_Tracking_System_ Across_the_World-as_Information_ Systems_in_higher_Education_Decisionmaking_Process [Online, Accessed May 2021]

Orr, Dominic. (2015). Two approaches to graduates in tracking systems (an interview). Agenda. 7. 18-21, https://www.researchgate. net/publication/294534341_Two_ approaches_to_graduates_in_tracking_ systems_an_interview [Online, Accessed May 2021]

http://iccd.unwe.bg/ [Online, Accessed May 2021]

https://www.unwe.bg/ [Online, Accessed May 2021] 